University of Pennsylvania Carey Law School

Penn Law: Legal Scholarship Repository

Faculty Scholarship at Penn Law

2-15-2020

\title{
Testing for Negative Spillovers: Is Promoting Human Rights Really Part of the "Problem"?
}

\author{
Anton Strezhnev \\ University of Chicago \\ Judith G. Kelley \\ Duke University \\ Beth A. Simmons \\ University of Pennsylvania Carey Law School
}

Follow this and additional works at: https://scholarship.law.upenn.edu/faculty_scholarship

Part of the Human Rights Law Commons, International Humanitarian Law Commons, International Law Commons, International Relations Commons, Law and Politics Commons, Models and Methods Commons, Policy Design, Analysis, and Evaluation Commons, Public Law and Legal Theory Commons, and the Social Policy Commons

\section{Repository Citation}

Strezhnev, Anton; Kelley, Judith G.; and Simmons, Beth A., "Testing for Negative Spillovers: Is Promoting Human Rights Really Part of the "Problem"?" (2020). Faculty Scholarship at Penn Law. 2461.

https://scholarship.law.upenn.edu/faculty_scholarship/2461

This Article is brought to you for free and open access by Penn Law: Legal Scholarship Repository. It has been accepted for inclusion in Faculty Scholarship at Penn Law by an authorized administrator of Penn Law: Legal Scholarship Repository. For more information, please contact PennlawIR@law.upenn.edu. 
[PUBLISHED IN International Organization, 75 (1): 71-102. 2021.]

Testing for Negative Spillovers:

Is Promoting Human Rights Really Part of the "Problem"?

\author{
Anton Strezhnev \\ University of Chicago \\ a.strezhnev@gmail.com \\ Judith G. Kelley \\ Duke University \\ Judith.Kelley@duke.edu \\ Beth A. Simmons \\ University of Pennsylvania \\ simmons3@law.upenn.edu
}

Abstract

The international community often seeks to promote political reforms in recalcitrant states. Recently, some scholars have argued that, rather than helping, international law and advocacy create new problems because they have negative spillovers that increase rights violations. We review three mechanisms for such spillovers: backlash, trade-offs, and counteraction and concentrate on the last of these. Some researchers assert that governments sometimes "counteract" international human rights pressures by strategically substituting violations in adjacent areas that are either not targeted or are harder to monitor. However, most such research shows only that both outcomes correlate with an intervention -- the targeted positively and the spillover negatively. The burden of proof, however, should be as rigorous as those for studies of first-order policy consequences. We show that these correlations by themselves are insufficient to demonstrate counteraction outside of the narrow case where the intervention is assumed to have no direct effect on the spillover, a situation akin to having a valid instrumental variable design. We revisit two prominent findings and show that the evidence for the counteraction claim is weak in both cases. The article contributes methodologically to the study of negative spillovers in general by proposing mediation and sensitivity analysis within an instrumental variables framework for assessing such arguments. It revisits important prior findings that claim negative consequences to human rights law and/or advocacy and raises critical normative questions regarding how we empirically evaluate hypotheses about causal mechanisms.

Acknowledgments: We thank Emilie Hafner-Burton and Yonatan Lupu for sharing their data and commenting on earlier versions of this idea. Thanks also to Aila Matanock, Sarah Bermeo, Jason Klocek, Charlie Clotfelter, Geoffrey Dancy, Chris Fariss, Yuqing Hu, Tana Johnson, Emily Ritter, John Singleton, Michael Ward, Will Moore, Yiqing Xu, and Wei Song for insightful comments on earlier drafts. 
Policymakers and scholars have long been concerned with the efficacy of international efforts to reform recalcitrant states. Studies have focused on the effectiveness of a range of tools from military interventions and sanctions to softer methods such as shaming and persuasion or facilitative instruments such as treaty commitments, education, and capacity training to achieve political reform. One area that has elicited close scrutiny has been efforts to improve human rights. Have norms ensconced in international law helped guide the development of better practices and protections? Have efforts to expose human rights violations incentivized better government behavior? For a long time, research concentrated on demonstrating positive effects; the null hypothesis was ineffectiveness.

As human rights research has matured, scholars have started asking whether wellintended interventions sometimes may have benefits while also causing harm. ${ }^{1}$ For example, has civil society advocacy simply caused flagrant rights violations to become stealthier? Have international legal commitments proscribing specific behaviors, such as political imprisonment, diverted abuses to worse outcomes like disappearance? Have rights commitments crowded out development objectives? Is all the attention on negative rights responsible for fleeting attention to social justice and equality? In short, is the rights agenda virtually doomed not only to be ineffective but to cause more damage to humankind than it has done good?

\footnotetext{
${ }^{1}$ On the unintended consequences of human rights interventions such as international law and advocacy, see Conrad and DeMeritt 2014; Hafner-Burton 2008; Kennedy 2002; Lupu 2013; Posner 2008; Simmons and Strezhnev 2017. This focus has also been prominent in the foreign aid and sanctions literature. See Ahmed 2012; Morrison 2009; Weiss et al. 1997; Wood 2008. See also the rule-of-law literature Carothers 2003; Kleinfeld 2012 and the democracy literature Kelley 2011; Simpser and Donno 2012.
} 
Such questions are important for both scholars and practitioners. Given their focus on constrained or adaptive human behavior, these questions can inform the ongoing theoretical debate about the relationship between international and national actors, law and politics, and civil society and government agents. Such questions hold tremendous policy relevance. Advocates and policymakers must consider the benefits and the costs of their actions, as well as their distributional and moral consequences. This is not possible, however, if unintended consequences are not fully examined and incorporated. Scholars are right to ask questions about possible negative effects of policy interventions.

As important as it is to study an intervention's negative spillovers, it is also important to recognize that this study is fraught with challenges. Appropriately, tests for first-order consequences have confronted the plethora of typical methodological criticisms surrounding causal inference, but claims of second-order, unintended consequences often do not garner such a hard kick to the evidentiary tires. Social scientists should not give unintended consequences a causal pass. Good social science and sound policy advice demand that we test for the mechanisms suspected of negative effects just as thoroughly as we do the causal mechanisms associated with first-order positive claims and articulate clearly the evidence for the mechanism leading to net negative outcomes. The famous Downs, Rocke, and Barsoom caution that we cannot attribute compliance to states that ratify treaties because they were going to improve anyway is conversely apt. ${ }^{2}$ When bad states do bad things and get criticized for it, the same logic must apply, with a symmetrical burden of proof. Too few researchers ask

\footnotetext{
${ }^{2}$ Downs, Rocke, and Barsoom 1996.
} 
whether the bad news about repression is bad news about international law and/or human rights advocacy, or were these states going to misbehave anyway?

We call attention to the evidentiary deficits in much of the research on negative spillovers from the promotion of human rights norms and offer a rigorous way to test such claims. We first describe three distinct mechanisms through which human rights interventions are said to cause negative consequences: backlash, trade-offs, and counteraction. Claims of these consequences crop up repeatedly in the critical human rights literature as unintended spillovers caused by well-intended but naive human rights interventions, such as international legalization, enhanced monitoring, or human rights advocacy.

After discussing these mechanisms, we focus specifically on counteraction and propose a rigorous way to detect its presence. We highlight how finding evidence of counteraction can be understood as a form of mediation analysis and illustrate how the approaches taken in the existing literature can be formulated as instrumental variables (IV) designs. In attempting to identify the effect of a variable targeted by an intervention on an unintended spillover quantity, the intervention is essentially assumed to act as an instrument, affecting the spillover only through its effect on the targeted outcome. Such a relationship is often implausible and so our proposed method provides a sensitivity analysis to relax this implicit assumption. ${ }^{3}$ The goal is to decompose the observed effect of the intervention (for example, a treaty commitment, an advocacy effort) into indirect

\footnotetext{
${ }^{3}$ Within the literature on international organizations, sensitivity analyses are a rare but increasingly valuable tool for evaluating the robustness of research designs. Most applications focus on assessing sensitivity of effect estimates in observational designs to unobserved confounding - for example, see Chaudoin, Hays, and Hicks 2018 which uses a variety of placebo tests on theoretically unrelated outcomes to illustrate likely biases in designs estimating the effect of treaty adoption.
} 
and direct components (the former flow through the change in the intended target quantity, while direct components are unintended by the intervener, and might include a range of reactions or trade-offs). This sensitivity analysis holds fixed the direct effect at a range of feasible values and provides estimates of the implied indirect effects. We apply this approach to two prior studies that warn of counteraction to illustrate what this method can reveal when the evidence for counteraction is weak to non-existent. Although our substantive focus here is on human rights, our approach applies to other issue areas as well. The broader purpose is to strengthen causal inference about specific mechanisms through which spillovers might occur.

\section{Human Rights and Unintended Consequences}

International efforts to promote human rights have been said to "produce" harm in several ways. The research can be distilled to three mechanisms: backlash, trade-offs, and counteraction (Table 1).

\section{TABLE 1 ABOUT HERE}

Backlash is often said to be a consequence of external norms and rights advocacy. Backlash refers to a strong, negative, public, and often angry societal reaction to political or social change. It is a social reaction rather than an individual response or a calculated policy decision, ${ }^{4}$ and it may worsen other rights, or lead to entrenchment or regress on

\footnotetext{
${ }^{4}$ Which is why it often is featured in analyses of advocacy for contested social issues such as freedom of religion (Rafi and Chowdhury 2000) and nondiscrimination on the basis of sex or sexual orientation (Epprecht 2012).
} 
the targeted right. ${ }^{5}$ For example, in some societies, external pressure to promote women's rights could lead to a doubling-down on more conservative social demands by opponents of such rights, and eventually even alter policies. In contrast to trade-offs and counteraction (discussed later), backlash tends to be public and defiant. Backlash can be and often is instigated at the top by power holders who are in some way threatened by the assertion of a rights claim and thus are motivated to stir up opposition to particular human rights practices or to foreign influence in general. ${ }^{6}$ It can be a direct response to criticism (for example, nationalist sentiments in response to foreign shaming) ${ }^{7}$ or it can be indirect (e.g., operate through a rights improvement which in turn provokes social or political opposition). While backlash can describe any form of opposition -- some scholars describe "liberal" backlash against rights violations for example ${ }^{8}-$ - we understand it as reasonably broad-based countermobilization against international human rights law, advocacy, or practice, whether or not rights improvements are realized on the ground. ${ }^{9}$

Theorists of social movements see backlash as a common though hardly an inevitable occurrence in response to challenges to existing power structures or norms. ${ }^{10}$

\footnotetext{
${ }^{5}$ Some scholars use the word backlash to include considered public policy choices (see, for example, Helfer 2017; Sikkink 2013) but here we distinguish social reactions from policy choices meant to reverse or blunt a human rights constraint (counteraction, discussed later). Sometimes these concepts merge and overlap, for example, when a well-entrenched official structure is deeply and widely embedded in society, like the "backlash" of the communist party prior to the dissolution of the Soviet Union (Thomas 2001, chapter 6) or religious officials in religious societies. Rafi and Chowdhury 2000.

${ }^{6}$ Vinjamuri 2017, 120//---//22.

${ }^{7}$ Snyder 2019.

${ }^{8}$ Vinjamuri $2017,116,118$. There is also literature suggesting backlash to right abuses, for example, arguing that torture increases violent opposition and the incidence of terrorism (Daxecker 2017) or that the torture memos elicited backlash against the Bush administration (Sikkink 2013).

${ }^{9}$ This definition may involve but goes well beyond negative individual emotional responses to criticism documented in the psychology literature (e.g., Scheff 2000).

${ }^{10}$ Tsutsui, Whitlinger, and Lim 2012. Quantitative research that finds at least short-run positive consequences to human rights shaming efforts include Bell, Clay, and Murdie 2012; Franklin 2008.
} 
Some go further to claim a causal chain of events that runs from international human rights law/advocacy to domestic anti-government mobilization, ${ }^{11}$ which then triggers backlash, which in turn contributes to worsening repression. The exact consequences are not always clear, but Hopgood, Snyder, and Vinjamuri claim that backlash may be associated with "pernicious, longer-term effects that may lock in regressive practices,"12 including strategically altering laws and institutions that are more likely to violate rights than to protect them. This is an important claim that runs in the opposite direction of much research claiming that law and advocacy helps rights claimants to mobilize for human rights, with generally positive consequences. ${ }^{13}$ Importantly, however, such claims need to be tested with carefully specified models; if the claim is that human rights law and advocacy have caused backlash, then it is critically important to show that any regression in rights is not simply a symptom of broader authoritarian trends. ${ }^{14}$

Tradeoffs. A second genre of critique is that the international human rights regime promotes specific legal rights at the expense of other human values. The claim is constructed around a notional resource constraint that implies that effort dedicated to human rights necessarily reduces resources available for other desirable ends. There are several variations on the trade-offs theme. Interventions that press for human rights could unintentionally divert funds from development projects; ${ }^{15}$ they could increase attention to negative rights, while distracting attention from economic and social rights; ${ }^{16}$ they could

\footnotetext{
${ }^{11}$ This step of the argument is the focus of Murdie and Bhasin 2011 who present evidence that the nature and degree of anti-government mobilization is conditional on the source of what they call "shaming."

${ }^{12}$ Hopgood, Snyder, and Vinjamuri 2017, 312.

${ }^{13}$ Simmons 2009.

${ }^{14}$ Ambrosio 2016.

${ }^{15}$ Posner 2008.

${ }^{16}$ Moyn 2010.
} 
denigrate human needs that cannot be formulated in rights terms at all ${ }^{17}$ they could favor one protected category of people at the expense of others, ${ }^{18}$ and so forth. Eric Posner, perhaps the bluntest proponent of this argument, asserts that "human rights obligations interfere with welfare-promoting activities of the government, and these welfarepromoting activities should be given priority." 19

These arguments all assume that a human rights trade-off occurs when power holders improve their policies in the area the intervention targets, but these improvements worsen nontargeted values, such as economic growth, justice, or equality. The choice to respond to the external intervention is strategic, but the result (better rights leading to poorer growth, worsening equality, or shoddy social justice) is undesired and unintended by both the pro-rights intervenors and likely even the targeted respondent.

Logically, for a trade-off to exist, the targeted rights and the outcome would have to be strict substitutes and not complements. ${ }^{20}$ That is, we would have to believe that the prioritized rights such as fair trials, women's political equality, freedom of conscience, or a child's right to health care do not themselves make a positive net contribution to other aspects of human welfare, such as economic development, tolerance, or justice. "Foregrounding" arguments -- the idea that advocating right $\mathrm{M}$ causally reduces attention and therefore attainment of right $\mathrm{Y}$-- have a similar trade-off structure, though typically

\footnotetext{
${ }^{17}$ Kennedy 2004.

${ }^{18}$ Hurd 2017.

${ }^{19}$ Posner 2008.

${ }^{20} \mathrm{We}$ are more interested in the logical structure of the trade-off argument here, but it is worth noting that the weight of existing research suggests it is highly implausible, primarily because most human rights and other welfare outcomes are complements not competitors. On the link between education and economic development see Fägerlind and Saha 2014; on the positive developmental impact of closing the educational gap for disadvantaged ethnic groups see Calver 2015; on the impact of both health and education on productivity and growth, see Alvi and Ahmed 2014; on the impact of adequate housing on development see Harris and Arku 2006.
} 
they are made in cognitive rather than strict budgetary terms. Elizabeth Hurd argues, for example, that protecting religious freedom renders groups other than Christians, Hindus, and Jews "inaudible." ${ }^{21}$ Moreover, when religious freedom is a priority, "violations of human dignity that fail to register as religious infringements languish beneath the threshold of national and international recognition as the international community dedicates limited resources to rescuing persecuted religionists." 22 For Posner, advocating human rights competes with human welfare; for Hurd, advocating religious rights competes with the rights of women, racial minorities, and the disabled. For these claims to hold, there must be a negative effect of a targeted right on a "spillover" outcome; otherwise, there is no reason to believe that a causal resource trade-off, whether tangible or cognitive, exists. So far, we have seen little systematic evidence of these claims, and none that would pass traditional tests for causality. ${ }^{23}$ And yet, such claims easily morph into causal claims and, even more dangerously, claims that rights advocates are inflicting real harm. ${ }^{24}$

Finally, we define a particular type of harm that we call counteraction, our focus in the rest of this article. Assuming an intervention seeks to spur improvements in human rights, counteraction occurs when power holders respond to the intervention by improving their behavior for the specific rights the intervention targets but then offsett these improvements by increasing other types of misconduct. It is a strategic response by a government to circumvent international pressure to improve its conduct in a particular

\footnotetext{
${ }^{21}$ Hurd 2017, 208.

22 Ibid., 204. It is not clear whether Hurd means cognitive or budgetary resources; for our purposes it could be either or both.

${ }^{23}$ See the discussion in Simmons and Strezhnev 2017.

${ }^{24}$ For example, volume editors Hopgood, Snyder and Vinjamuri summarize Hurd's contribution as showing that "the very activities of human rights promoters may bring about a deterioration in the longterm prospects for human rights observance.” Hopgood, Snyder, and Vinjamuri 2017, 18.
} 
issue area. Like trade-offs that may be made under budgetary or cognitive constraints, counteraction spurs improvements in the targeted area $\mathrm{M}$ but reduces rights in the spillover areas Y. It differs from interventions that merely displace the same or nearly identical type of misconduct by simply moving it to a different time or place, thus rendering the intervention (merely) ineffective in changing the net effect on the targeted behavior. ${ }^{25}$ Instead, counteraction involves shifts between different types of misconduct so that the intervention may cause new types of problems or increase the severity of another set of problems. It is fundamentally a causal hypothesis about the effect that changes in one form of behavior have on another area. It inherently involves first a rights improvement, the consequences of which government agents seek to reverse with alternative forms of repression. In contrast to backlash, which is a social reaction and can be either the direct response to shaming alone or a response to targeted rights improvements that social forces then lash back against, counteraction suggests that protecting targeted rights causes compensatory strategic repression in another area and may, depending on how one weighs the costs and benefits, do more harm than good.

One of the most in-depth discussions of counteraction is the qualitative study of torture by Darius Rejali who argues that high-quality human rights monitoring has led to innovative forms of stealth torture, even (or especially) in democracies. ${ }^{26}$ Quantitative studies have also sought to document counteraction. ${ }^{27}$ For example, Hafner-Burton

\footnotetext{
${ }^{25}$ For example, in a study of Ghana, Ichino, and Schundeln 2012 found that domestic monitoring merely shifted excess voter registration to unmonitored areas. The type of problem did not change//--//it just moved elsewhere. It also differs from cases, which we suspect are rare, in which an intervention causes positive consequences in some countries but negative consequences of the same kind elsewhere (sets of states may be heterogenous). Conrad and Ritter 2013.

${ }^{26}$ Rejali 2007. However, while such substitution has been found to occur, Rejali comes closer to claiming that monitoring has not been effective than claiming that is has net negative effects.

${ }^{27}$ In the next section we show these studies do not use methods that support causal inferences.
} 
claims that international shaming improves political rights, but that it also "often" correlates with more political terror, ${ }^{28}$ and suggests that one possible explanation is that "governments are strategically using some violations to offset other improvements they make in response to international pressure to stop violations. ${ }^{29}$ Similarly, Conrad and McDermitt find that when the United Nations shames countries specifically for torture, political rights deteriorate. ${ }^{30}$ Likewise, Lupu notes that countries that ratify the International Covenant on Civil and Political Rights (ICCPR) improve political rights but have more victims of disappearances. He cautiously suggests that "if the cost of using certain types of repressive techniques increases, governments may become more likely to use other, less costly options." 31

Given their appeal to governments who want to maintain power by hook or by crook, such claims seem plausible and perhaps even intuitive. However, there are also reasons that the appearance of these various spillovers may be deceptive. Despite its theoretical appeal, counteraction may not be the most plausible -- and certainly not the only -- mechanism for explaining an observed correlation between a given behavior and a particular international (or for that matter, domestic) intervention. ${ }^{32}$

All three mechanisms through which scholars make claims that international human rights interventions have had negative consequences have the same evidentiary burdens as any other causal claim. Such claims go well beyond skepticism that such interventions are merely ineffective. That human rights interventions have not eliminated

\footnotetext{
${ }^{28}$ Hafner-Burton 2008 See also, for example, Dreher, Gassebner, and Siemers 2012; Murdie and Davis 2012.

${ }^{29}$ Hafner-Burton 2008.

${ }^{30}$ Conrad and DeMeritt 2014.

${ }^{31}$ Lupu 2013, 492.

32 Moore 1998.
} 
rights abuses is hardly news, and we accept that it is the burden of the so-called optimists to demonstrate any improvements. But if backlash, trade-offs, and counteraction are claimed to worsen rights, then such claims are subject to similar demands that causality be scrutinized, possible spuriousness be taken seriously, and selection problems be considered.

\section{Methodological Focus: Modelling Counteraction}

The Problem: Modelling the Hypothesized Mechanism

Counteraction deserves attention because researchers have attempted to demonstrate its negative consequences. Yet the causal minefield is evident and there are several reasons to be skeptical about broad counteraction claims. The first issue is traditional selection effects. Arendt noticed well before there was much international shaming that dictators facing challenges to their rule often increase repression or torture. ${ }^{33}$ Considering the obvious selection effects should give scholars pause before jumping to conclusions about law and advocacy. ${ }^{34}$ Repressive governments behave badly in multiple areas; their patterns of rights violations tend to look more like complements than substitutes. ${ }^{35}$ Interventions such as shaming target countries with worsening rights create a classic selection effect. Thus, although Conrad and DeMeritt argue that "when a state is put on notice for torture, it responds by securing its own grasp on power, limiting empowerment rights," 36 they cannot rule out that the UN may simply shame countries

\footnotetext{
${ }^{33}$ Arendt 1970.

${ }^{34}$ Conrad and Ritter 2013; Vreeland 2008.

${ }^{35}$ Fariss and Schnakenberg 2014.

${ }^{36}$ Conrad and DeMeritt 2014, 22//---//23. This is a shift in the opposite direction of what Hafner-Burton 2008 suggested in response to more general shaming.
} 
with more, and possibly worsening torture, ${ }^{37}$ rather than cause more torture.

A further methodological problem that may lead us to question broad counteraction claims is that so far scholars have used separate models to test separately for correlation between the intervention and each outcome. For example, Lupu's finding that ratification of the ICCPR correlates with improved political rights and with increased victims of disappearances is based on two separate models that do not connect these correlations to one another. Contrary to his cautiously worded conclusion, ${ }^{38}$ this cannot demonstrate substitution. A difference in the intervention's effect on the targeted outcome and its effect on the substituted outcome implies only that there may be some combination of backlash, counteraction, trade-off, or simple spuriousness. Decomposing the underlying mechanisms requires additional assumptions.

Why should we be skeptical? First, the intervention may affect one outcome in one subset of observations but affect another outcome in another subset of observations. Since effects are identified as averages only, we cannot immediately conclude that these patterns reflect substitution at the level of the individual state. Second, the assumption that governments have a "menu of manipulation," 39 and can easily shift to new techniques of repression does not hold since repressors are already likely to choose the most efficient means of control. ${ }^{40}$ Third, and crucial for our method here, the effects of the intervention alone are not the quantity of interest for assessing counteraction. Counteraction implies a causal pathway linking the intervention, the targeted outcome, and the spillover. Thus, the targeted outcome must affect the spillover. Separate models

\footnotetext{
${ }^{37}$ Conrad and DeMeritt 2014, 15.

38 "Results provide empirical evidence that such substitution may occur." Lupu 2013, 492.

${ }^{39}$ Davenport 2007; Schedler 2002.

40 Moore 2000.
} 
thus suffice if and only if we assume counteraction is the only possible causal mechanism. This restrictive assumption is unlikely to hold in any real-world situation. It also effectively assumes away what a researcher is obligated to examine: how, exactly, do better rights demands make things worse? Under what conditions can we expect such causal deterioration? Causal mechanisms must therefore be scrutinized, which is more difficult than to provide evidence for overall correlations. ${ }^{41}$

A final reason to be skeptical of broad counteraction claims is that case studies often underscore the importance of heterogeneous contexts. Kuperman's findings that rhetorical support for human rights can backfire in civil war settings with heavily armed and revolutionary rebel groups is a highly conditional argument. ${ }^{42}$ So are the scope conditions for Risse and Sikkink's "spiral model," which requires a combination of transnational advocates, active domestic human rights organizations, and foreign government support to produce internalization of human rights norms. ${ }^{43}$ Switching between strategies in response to external norms or monitoring is likely highly constrained -- and certainly not similar -- for such heterogenous cases.

\section{Formalizing Counteraction Effects}

We propose a method for assessing the plausibility of counteraction when we observe an intervention's contrasting effects on two outcomes. ${ }^{44}$ We apply this approach to evaluate counteraction claims made by two influential studies. To start, we review the

\footnotetext{
${ }^{41}$ Green, Ha, and Bullock 2010.

${ }^{42}$ Kuperman 2004.

${ }^{43}$ Risse and Sikkink 1999.

${ }^{44}$ When backlash is mediated through rights improvements//--//that is, when the reaction is against the shift in rights enjoyment and not just foreign shaming//--//the model we suggest here is appropriate as well.
} 
framework for causal mediation analysis developed in Robins and Greenland and Pearl and introduced to political science by Imai, Keele, Tingley and Yamamoto. ${ }^{45}$ The causal quantities of interest are formalized using the conventional Neyman-Rubin potential outcomes framework. ${ }^{46}$ Assume a total of $N$ units, each indexed by $i$. Let $Y_{i}$ be the observed spillover or offsetting outcome of interest, $M_{i}$ be the observed outcome targeted by the intervention, and $A_{i}$ be the observed level of the intervention. For simplicity, we focus on the case of a binary $A_{i}$ and binary $M_{i}$ but our approach can be extended to continuous variables with additional modeling assumptions. Define $Y_{i}(a)$ as the potential offsetting outcome that we would observe if unit $i$ were assigned to take on an intervention value of $A_{i}=\mathrm{a}$. The intervention's total effect for unit $i$ is the difference $\tau_{i}=Y_{i}(1)-Y_{i}(0)$

Causal mediation methods focus on different ways to decompose the total treatment effect into a "direct" component and an "indirect" component attributable to some mediator $M_{i}$. To motivate these decompositions, we need to define additional counterfactual outcomes for both $Y_{i}$ and $M_{i}$, following standard practice in the mediation literature. First, we define $M_{i}(a)$ as the targeted outcome we would observe if unit $i$ were assigned intervention $A_{i}=a$. Then, we define a joint potential outcome, $Y_{i}(a, m)$, which denotes the potential offsetting outcome we would observe if unit $i$ were assigned $A_{i}=$ $a, M_{i}=m$. We further make the "composition" assumption that $Y_{i}\left(a, M_{i}(a)\right)=Y_{i}(a){ }^{47}$ Using this framework, we can define additional counterfactual comparisons that permit

\footnotetext{
${ }^{45}$ Imai et al. 2011; Pearl 2001; Robins and Greenland 1992.

${ }^{46}$ Neyman 1923; Rubin 1974.

${ }^{47}$ See VanderWeele and Vansteelandt 2009 for a broader discussion of the interpretation underlying this particular formulation.
} 
the decomposition of the overall treatment effect. ${ }^{48}$ The indirect or "causal mediation effect" for unit $i$, holding fixed the intervention at some level $a$ is defined as

$$
\delta_{i}(a)=Y_{i}\left(a, M_{i}(1)\right)-Y_{i}\left(a, M_{i}(0)\right)
$$

In other words, the indirect effect is the difference in potential outcomes when a unit is assigned the mediator value it would have under treatment compared to when that unit is assigned the mediator it would have under control.

Conversely, the direct effect represents the change in the potential outcome for $Y_{i}$ if the treatment were manipulated while the mediator is held constant at the level it would take under either treatment or control, $M_{i}(a)$.

$$
\zeta_{i}(a)=Y_{i}\left(1, M_{i}(a)\right)-Y_{i}\left(0, M_{i}(a)\right)
$$

The total effect $\tau$ for individual $i$ can be written as the sum $\tau_{i}=\delta_{i}(a)+\zeta_{i}(1-a)$ for $a=0,1$. In practice, researchers cannot directly estimate individual treatment effects and instead focus on decomposing the average treatment effect $\bar{\tau}$ into average direct and indirect effects, denoted $\bar{\zeta}(a)$ and $\bar{\delta}(a)$.

\section{FIGURE 1 ABOUT HERE}

Figure 1 illustrates the connection between the causal pathways linking $A, M$, and $Y$ and the three mechanisms discussed earlier. ${ }^{49}$ Figure 1 shows three possible causal arrows: (1) from $A$ to $M$, (2) from $M$ to $Y$, and (3) from $A$ to $Y$. The combination of paths

\footnotetext{
${ }^{48}$ Imai et al. 2011 refer to the indirect effect as the "causal mediation effect." Robins and Greenland 1992 term this the "pure indirect effect" when $a=0$ and the "total indirect effect" when $a=1$. See VanderWeele 2013, 2014 for alternative decompositions.

${ }^{49}$ Pearl 2000. For exposition, we omit the presence of observed confounders between $A$ and $Y$ along with observed and unobserved confounders of $M$ and $Y$.
} 
1 and 2 reflects the indirect effect of the intervention that flows through the targeted outcome. Path 1 reflects the effect of the intervention on altering the targeted outcome and path 2 the corresponding effect of that change in the targeted outcome on the spillover. Conversely, path 3 reflects the direct effect unmediated by $M$. Counteraction exists when (1) is positive and (2) is negative, implying an overall negative indirect effect of A on Y through M.

Trade-offs and rights-mediated backlash operate through an analogous mechanism. Direct backlash is captured in arrow (3), which denotes an effect of $A$ on $Y$ that carries through entirely through a non- $M$ mechanism. Notably, for a fixed overall effect of $A$ on $Y$, we can understand counteraction and direct backlash as competing explanations for the same phenomenon. The plausibility of counteraction as an explanation for A's negative effect on $\mathrm{Y}$ is strengthened when the direct effect (3) is either 0 or in a countervailing direction (positive). This intuition, which underpins many of the arguments for counteraction effects, motivates our proposed sensitivity analysis for assessing the indirect counteraction effect.

The path diagram approach to causal mediation in the social sciences has its roots in the structural modeling framework introduced by Baron and Kenny. ${ }^{50}$ This approach assumes a set of simultaneous equation models for the outcome and mediator:

$$
\begin{gathered}
Y_{i}=\alpha_{1}+\beta_{1} A_{i}+\xi_{1}^{\prime} X_{i}+\epsilon_{i 1} \\
M_{i}=\alpha_{2}+\beta_{2} A_{i}+\xi_{2}^{\prime} X_{i}+\epsilon_{i 2} \\
Y_{i}=\alpha_{3}+\beta_{3} A_{i}+\gamma M_{i}+\xi_{3}^{\prime} X_{i}+\epsilon_{i 3}
\end{gathered}
$$

\footnotetext{
${ }^{50}$ Baron and Kenny 1986. See Zhao, Lynch Jr, and Chen 2010 for a modern review.
} 
where $\epsilon_{i 1}, \epsilon_{i 2}, \epsilon_{i 3}$ are mean zero-error terms, and $X_{i}$ denotes a vector of pretreatment covariates.

In this framework, $\beta_{2}$ denotes the average effect of the treatment on the mediator, $\gamma$ the mediator's effect on the outcome, and $\beta_{3}$ the treatment's effect on the outcome holding constant the mediator. Researchers have often interpreted the product $\beta_{2} \gamma$ as the effect of $A$ on $M$ mediated by $Y .{ }^{51}$ Imai and colleagues provide a formal justification for this estimator in the context of the potential outcomes framework and give the necessary assumptions required to interpret $\beta_{2} \gamma$ as identifying the average causal mediation effect. In addition to correctly specified outcome and mediator models, identifying the causal mediation effect using the product of coefficients requires a sequential ignorability assumption. This consists of two parts: first, that the intervention is ignorable or assigned "as-if-random" conditional on pre-treatment covariates; second, that the mediator is ignorable conditional on covariates and treatment. This requires ruling out the presence of any confounders of the mediator and outcome that might be affected by treatment. While identifying controlled direct effects requires weaker assumptions ${ }^{52}$-- permitting $^{2}$ the presence of observed post-treatment confounders -- it still requires researchers to justify two ignorability assumptions: one for the intervention and another for the targeted outcome. While Imai et. al. develop a sensitivity analysis framework to relax the second part of sequential ignorability by allowing researchers to specify the degree of unobserved confounding of $M$ and $Y$ via the correlation between $\epsilon_{i 2}$ and $\epsilon_{i 3}$, we note that

\footnotetext{
${ }^{51}$ MacKinnon et al. 2002

${ }^{52}$ Acharya, Blackwell, and Sen 2016.
} 
it is often difficult for researchers to develop reasonable beliefs about the magnitude of this unobserved confounder and thereby interpret a sensitivity analysis.

We develop an alternative strategy that does not use sequential ignorability and builds on the approach already taken by researchers studying counteraction -- using the estimated effects of the intervention on the two outcomes. While we have pointed out that such an approach alone does not directly assess the presence of counteraction, it does provide the basis for a sensitivity analysis.

\section{Connecting the "Two Effects" Strategy to Instrumental Variables}

Among papers examining counteraction or trade-offs, it is extremely common to see researchers arguing for substitution based on an observed positive association between treatment $A$ and targeted outcome $M$ and an observed negative association between treatment $A$ and offsetting outcome $Y .{ }^{53}$ Our method starts from the necessary assumptions made to estimate these treatment effects: namely that there are no unobserved pretreatment confounders of $A$ and $M$ and $A$ and $Y$. Formally, researchers assume

$$
\left\{Y_{i}(a), M_{i}(a)\right\} \perp A_{i} \mid X_{i}
$$

What can those two effects tell us about the effect of $M$ on $Y$ ? As Imai and colleagues illustrated, randomization of $A$ does not suffice to identify the direct and indirect effects since it does not guarantee unconfoundedness of $Y_{i}\left(a, M_{i}(a)\right)$ and $M_{i}(a)$. Thus, randomization of A doesn't guarantee there is no other omitted variable causing

\footnotetext{
${ }^{53}$ A notable exception is Fariss and Schnakenberg 2014 who consider estimation of the overall dependence structure across multiple measures of repression over time. However, the goal in our study is not to estimate causal relationships between measures but to obtain an overall descriptive sense of how often these measures positively or negatively co-vary over time and across states.
} 
both the mediator and the outcome. Using an auxiliary variable to assess counteraction is structurally very similar to the well-studied problem of estimating effects via instrumental variables (IV). In this case, $A$ acts as an instrument for $M .{ }^{54}$ As in IV, the researcher's goal is to compare correlations between the instrument and the two other variables to infer something about their causal relationship. Angrist, Imbens, and Rubin formalize the IV assumptions in the potential outcomes framework and show that for the case of a binary $A$ and a binary $M$ when $A$ (1) is exogenous, (2) has a non-zero and monotonic effect on $M$, and (3) has no direct individual causal effect on $Y$ that is unmediated by $M$ ("exclusion restriction"), the treatment effect of $M$ on $Y$ is identified using the ratio of the effect of $A$ on $Y$ and the effect of $A$ on $M$-- the classic Wald ratio estimator. ${ }^{55}$ As the appendix shows, under these assumptions, the IV estimator identifies $M^{\prime} s$ direct effect on $Y$ for the subgroup for which $A$ has an effect on $M$ (the "complier" group). Additionally, researchers can incorporate covariates by assuming the linear structural models from the previous section and estimating $\gamma$ via two-stage least squares, even in the presence of an unobserved confounder of $M$ and $Y$

What additional assumptions are needed to apply the IV framework to mediation analysis? We have already assumed (1) by virtue of assuming the (conditional) ignorability of treatment $A$. Likewise, (2) can be partially tested from the data and rejected in the absence of a strong first-stage effect of $A$ on $M$. Assumption (3) is the necessary third element and is particularly questionable in the counteraction setting

\footnotetext{
${ }^{54}$ This connection between IV and identification of path effects in mediation analysis has been mentioned in the existing literature, most notably in Sobel 2008.

55 Angrist, Imbens, and Rubin 1996; Wald 1940. Notably, this effect is a "local" average treatment effect, defined for the subsample of units which are compelled by the instrument to change their level of M. While in many applications of IV, this is not necessarily a theoretically interesting group, for the purposes of evaluating counteraction it is actually the precise subpopulation of interest.
} 
because it would imply that the intervention's direct effect on the offsetting outcome would be 0 for all units, regardless of the targeted outcome's level. Indeed, a strict exclusion restriction assumption would rule out all possible mechanisms by which A affects $\mathrm{Y}$ besides counteraction, effectively assuming what researchers set out to examine.

While researchers are unlikely to believe the exclusion restriction holds exactly with respect to the treatment $A$, they may nevertheless have beliefs about the size and direction of $A^{\prime}$ s direct effect on $Y$. A sensible question to ask is: "Given varying beliefs about the exclusion restriction violation, do the observed effects of $A$ on $M$ and $A$ on $Y$ still support a counteraction story?" We suggest that applied researchers may still find the IV strategy useful for assessing counteraction when combined with a formal sensitivity analysis for the exclusion restriction. Our proposed approach resembles existing methods for conducting formal sensitivity analyses for the assumption of "no omitted variables" in observational studies. ${ }^{56}$ These approaches assess a given causal effect's robustness by reestimating the result under varying levels of assumed omitted variable bias. Findings that remain statistically significant for a large range of potential omitted variable biases are considered relatively robust to violations of the assumption. Our approach adopts the same linear structural equation framework as the sensitivity analysis for sequential ignorability proposed by Imai and colleagues, but manipulates a different sensitivity parameter. Instead of assessing the magnitude of omitted variable bias confounding $M$

\footnotetext{
${ }^{56}$ See Cinelli and Hazlett 2018; Imbens 2003; Oster 2019. For a general overview of sensitivity analysis techniques in observational studies, see Rosenbaum 2002.
} 
and $Y$ that would break a result, it instead examines the magnitude of the direct effect of $A$ on $Y$ that would break the IV estimate of the effect of $M$ on $Y$.

The particular approach to sensitivity analysis we propose here is similar to that proposed by Conley, Hansen, and Rossi ${ }^{57}$ for general violations of "exogeneity" in IV. To briefly describe our approach, suppose that we knew the true direct effect of $A$ on $Y$ for each unit. We could then subtract this effect from the observed outcome to generate a new outcome $Y^{*}$ which the exclusion restriction holds for by definition. Applying the standard instrumental variables analysis to the transformed outcome would then give a valid estimate for the counteraction effect under the assumed violation. Repeatedly carrying out this process for a range of feasible direct effects provides a set of possible estimates for the counteraction effect. Under the linear structural equation framework, we can estimate the effect of the mediator using a two-stage least squares (2SLS) estimator. ${ }^{58}$ This commonly used approach to estimating IV effects allows researchers to parsimoniously incorporate covariates in addition to handling situations where $A$ is not necessarily binary. While this approach does make some additional assumptions regarding effect homogeneity and correct model specification, these assumptions approximate what researchers are already assuming to estimate the effects of policy interventions using linear regression. ${ }^{59}$ Existing sensitivity analyses for mediation also

\footnotetext{
${ }^{57}$ Conley, Hansen, and Rossi 2012; Ertefaie et al. 2017; Huber 2014; Kraay 2012.

${ }^{58}$ Angrist and Imbens 1995.

${ }^{59}$ The assumption of constant treatment effect, for example, is not critical for interpreting the IV estimates. As Angrist and Imbens 1995 illustrate, the 2SLS estimator is equivalent to a weighted average of treatment effects across covariate strata. This is generally true of any regression-adjustment approach for estimating average treatment effects. See Aronow and Samii 2016. Additionally, the assumption of correct model specification is a prerequisite to nearly any observational study using regression adjustment.
} 
rely on the linear structural equation framework for simplicity. ${ }^{60}$ We discuss the assumptions in greater detail in the appendix.

The "first-stage" linear regression assumes the following model for $\mathrm{M}$

$$
M_{i}=\alpha_{2}+\beta_{2} A_{i}+\xi_{2}^{\prime} X_{i}+\epsilon_{i 2}
$$

where $X_{i}$ denotes a vector of pretreatment covariates, $\xi_{2}^{\prime}$ a vector of parameters, and $\epsilon_{i 2}$ is a mean zero-error term with finite variance. The parameter $\beta_{2}$ denotes the average effect of $A$ on $M$. Under conditional ignorability of treatment, this can be estimated consistently via OLS since $E\left[\epsilon_{i 2} \mid A_{i}, X_{i}\right]=0 .^{61}$ We assume another model for the outcome $Y_{i}$ :

$$
Y_{i}=\alpha_{3}+\gamma M_{i}+\xi_{3}^{\prime} X_{i}+\epsilon_{i 3}
$$

Note that $A_{i}$ does not appear in this model, consistent with the exclusion restriction. After estimating the first-stage regression via OLS, the fitted values $\widehat{M}_{\iota}$ are plugged into a second regression with $Y_{i}$ as the outcome along with the same covariates $X_{i}$ from the first stage. This yields a consistent estimate of the coefficient $\gamma$ even when sequential ignorability does not hold and $E\left[\epsilon_{i 3} \mid A_{i}, M_{i}, X_{i}\right]$ does not equal 0 -- that is, the outcome and mediator model error terms are correlated.

As discussed, the exclusion of $A_{i}$ from the outcome model is an implausible assumption in most empirical settings. To implement our sensitivity analysis, we assume the following outcome model:

$$
Y_{i}=\alpha_{3}+\rho A_{i}+\gamma M_{i}+\xi_{3}^{\prime} X_{i}+\epsilon_{i 3}
$$

\footnotetext{
${ }^{60}$ See Imai et al. 2011 for a generalization of the mediation sensitivity analysis for sequential ignorability to other outcome models.

${ }^{61}$ One implicit IV assumption not discussed in the previous section is that the effect of $A$ on $M$ is monotonic for all units in the sample, which the structural model here implicitly assumes by treating $\beta_{2}$ as constant. Monotonicity requires that the treatment effect of the policy on the targeted outcome cannot be positive for some units and negative for others.
} 
and assume that $\rho$ is a known constant parameter. This corresponds to a model where, in addition to its effect on $M_{i}, A_{i}$ also has a constant direct effect on $Y_{i}$ equal to $\rho$. This allows us to define an augmented outcome $Y^{*}$ for which the exclusion restriction holds by definition.

$$
Y_{i}^{*}=Y_{i}-\rho A_{i}
$$

For a reasonable set of values of $\rho$, we propose researchers estimate the IV effect of $M$ on $Y^{*}$ and plot the resulting point estimates and confidence intervals against each choice of $\rho$. While we are assuming a constant $\rho$-- and by extension a constant treatment effect -this is not an absolute requirement. In principle, a researcher could allow $\rho$ to vary across units, though visualizing and interpreting the analysis with more than two sensitivity parameters becomes rather challenging. In the appendix, we go further into the interpretation of $\rho$ and its relation to sensitivity parameters used in other suggested sensitivity analyses.

How should researchers choose what values of $\rho$ are feasible? By definition, $\rho$ itself depends on the scale of Y. We propose two approaches to assessing what would be considered a "reasonable" direct effect. The first is to standardize $\rho$ and compare against common benchmarks. A variety of possible standardizations exist -- we consider a frequently used approach for standardizing effects of binary variables: Cohen's d. This quantity is defined as the unstandardized effect divided by the pooled standard deviation of the outcome $Y_{i}$, denoted $s$.

$$
d=\frac{\rho}{S}
$$


Transforming $\rho$ to $d$ allows us to evaluate the posited direct effects on a common scale - in terms of standard deviations of the outcome ${ }^{62}$ Cohen provides a set of benchmarks for determining what constitutes a "small," "medium," and "large" effect which can be combined with theoretical expectations regarding the direct effect of $Y_{i}$ to determine the plausibility of each IV estimate.

As an alternative to using these generic benchmarks, which may not necessarily represent what is considered a "large" or "small" effect in the particular case being studied, we also suggest benchmarking against the estimated effects of $A_{i}$. This is similar in spirit to the strategy used by Imbens for assessing the sensitivity estimatesto unobserved confounding which compares the amount of confounding that is found to break the finding to other known effects of variables in the data. ${ }^{63}$ The estimated effect of $A_{i}$ on $M_{i}$ provides one reasonable benchmark because, in the case of human rights violations, researchers typically have some theoretical beliefs about what types of rights the policy intervention is likely to affect the most. It is often the case that a researcher believes that any effect of $A_{i}$ will be largest for the targeted outcome and any direct effect on the spillover outcomes is unlikely to be any larger. Given these beliefs, a researcher would constrain the range of the sensitivity parameter $d$ to be no larger than the standardized effect of $A_{i}$ on $M_{i}$.

\section{Examples: International Treaties, Norms, and Shaming}

\footnotetext{
${ }^{62}$ Cohen 1992.

${ }^{63}$ Imbens 2003.
} 
We apply our framework to two of the studies that make counteraction claims with respect to human rights: Hafner-Burton and Lupu. ${ }^{64} \mathrm{Hafner-Burton}$ has been well-cited for arguments about the negative consequences of international interventions. ${ }^{65}$ Both studies, in whole or in part, use country-year measures of respect for rights drawn from the Cingranelli and Richards (CIRI) data set. Hafner-Burton evaluates the effect of international naming and shaming by nongovernmental organizations (NGOs), international organizations such as the $\mathrm{UN}$, and the news media on measures of human rights, while Lupu estimates the effect of ICCPR ratification on the extent to which governments protect both civil rights (e.g., speech, association, assembly, religion) and physical integrity rights. In both studies, the presence of a positive correlation between an intervention and a country's respect for one set of rights and a second, negative correlation between that intervention and respect for another set of rights is taken as evidence for the counteraction hypothesis. We show that in both cases, the evidence is insufficient to support counteraction.

In replicating Hafner-Burton, we find no strong or statistically significant effect of NGO shaming on political rights and only weak evidence for an adverse effect on physical integrity rights. In this case, the argument for counteraction fails the first necessary criterion for counteraction: that the policy intervention affects the targeted outcome. Even if one is to accept the presence of the effect on physical integrity rights, the absence of any corresponding change in political rights directly contradicts the hypothesis that states are "trading off" rights. In the case of Lupu, we do find some

\footnotetext{
${ }^{64}$ Hafner-Burton 2008; Lupu 2013.

${ }^{65}$ For citations of this finding of Hafner-Burton see, for example, Conrad and DeMeritt 2014; Conrad and Moore 2010; Dreher, Gassebner, and Siemers 2012; Murdie and Davis 2012. The article has been cited nearly 600 times.
} 
evidence of the primary effect on the targeted outcome -- ratification improves some measures of civil rights. However, illustrating the usefulness of the sensitivity analysis, in applying it, we find that the true, unmediated effect of ICCPR ratification on physical integrity rights would have to be much larger than is theoretically plausible to sustain the counteraction argument.

First, we turn to Hafner-Burton's analysis, which considers the effects that international naming and shaming campaigns have on governments' respect for civil liberties and for personal integrity rights. The article's strongest results are for the effect of naming and shaming by an NGO -- Amnesty International (AI) -- on abuses of physical integrity rights. We focus specifically on replicating the country-year OLS results presented in Table 2 with a few important modifications.

Hafner-Burton measures physical integrity rights violations using a composite index of repression obtained by adding together the CIRI scores for the four physical integrity measures: killing, torture, imprisonment, and disappearances. This yields a variable that ranges from 0 (no violations on any of the four measures) to 8 (worst scores on all four measures). This is then regressed using OLS on a measure of NGO advocacy and shaming obtained by summing the number of press releases and background reports that $\mathrm{AI}$ issued for a given country in a given year and then taking the log, rescaling the measure to have mean $0 .{ }^{66}$ The regression models also include indicators for whether a state has signed the Convention Against Torture and the ICCPR respectively, a measure of democracy that coarsens the conventional Polity IV scale into a binary indicator based on whether the score is above or below 6 , the logged GDP per capita in a given country

\footnotetext{
${ }^{66}$ While not clearly stated in the original paper, country-year observations with zero AI press releases or reports were arbitrarily coded 0.1 to avoid problems with taking the $\log$ of 0 .
} 
year, the log of population, and whether the country is experiencing a civil war or an interstate war. All of these regressors are lagged by one year. In addition to these covariates, the models include lags of the outcome variable. For the physical integrity rights outcome, one-, two-, and three-period lags of the outcome are included as regressors along with time fixed-effects. Hafner-Burton then regresses a measure of political rights using the same model specification except with only the one-period lagged outcome included as a regressor. The political rights measure comes from ratings done by Freedom House and ranges from 0 (no violations) to 6 (extreme repression).

While the results presented in this regression suggest AI shaming has the effect of worsening repression, they do not, in the same regression, present evidence that shaming also has a statistically significant positive effect on political rights. Rather, the combined argument for counteraction appears to come from the combination of different regressions on different time spans, with different identification strategies, some of which show an effect on one form of rights and some on another. ${ }^{67}$ Even when using similar selection-on-observables identification strategies, the effects presented are identified on two different subsamples: Freedom House scores are available as far back as 1972 for some states while the CIRI scores start in the early 1980s. Combining these results to infer counteraction is problematic not only because they do not by themselves imply the existence of a counteraction effect (as our sensitivity analysis technique shows), but they may also not even imply the existence of both effects for a common set of states. Effect

67 Table 3 in Hafner-Burton 2008 uses instruments and finds the statistical significance of the terror relationship with shaming disappears but that shaming is associated with higher political rights. Table 4 in Hafner-Burton 2008 isolates effects to different regions, finding a significant association between shaming and higher terror and a significant association between shaming and better political rights in the Asia and America regions. 
heterogeneity, both over time and across units means that at a minimum, data-driven arguments for substitution or trade-off need to show effects on a common population.

We replicated these results with a few adjustments and corrections to the original data set. First, we estimated the effects on both outcomes only for the period for which data on both political and physical integrity rights (including the required lags) were available: 1984 to 2001. Second, we addressed an issue in the original data in which numerous observations were missing data on population. This gave us a slightly larger time-series cross-sectional data set than the one presented in the original paper $(2,173$ versus 1,828 country-years) and corrected for the possibility that these were not missing at random. Third, we rescaled the logged shaming measure so that it had a standard deviation of 1 to help aid in interpreting the regression coefficients. Finally, in addition to estimating the original specifications, we estimated two specifications for the physical integrity rights measure with fewer lagged outcome variables. Figure 1 presents the estimated effect of a one-standard-deviation increase in the AI shaming measure for all four models.

\section{FIGURE 2 ABOUT HERE}

We find a slight but statistically insignificant effect of NGO shaming on improved political rights. Additionally, if we accept Hafner-Burton's original identification strategy and use three lags of the outcome in the regression, we fail to find a statistically significant effect of shaming on the physical integrity itself. Only when we drop all but a single lag do we recover the original, statistically significant finding. However, this is 
likely driven by omitted variable bias if we believe that Amnesty International's propensity to shame a given country is influenced by multi-year trends in abuses over time.

Even if we accept that identification is credible given a single period lag, the results would be enough to show an effect on only physical integrity rights and not counteraction between political and physical integrity rights. This is because, as we set out, showing the former using the dual correlation method requires a first-stage effect on the targeted outcome. This is both a theoretical and practical concern -- if the policy is doing nothing to alter the targeted outcome then there exists no constraint in the way that the counteraction hypothesis suggests. Practically, credible inference on treatment effects via instrumental variables techniques requires a strong first-stage effect. When instruments are "weak," point estimates and standard errors based on asymptotic approximations, as in the case of 2SLS, are biased and have particularly poor performance. ${ }^{68}$ This can be seen intuitively from the form of the 2SLS estimator in the single instrument/single endogenous variable case, which is a ratio of two OLS coefficients. When the denominator is close to 0 (no effect of A on M), the resulting 2SLS estimate will be extremely large and extremely variable. We therefore omit presenting a sensitivity analysis of the Hafner-Burton result since the results fail to show even the minimum necessary conditions for counteraction to be plausible and, indeed,

\footnotetext{
${ }^{68}$ A number of thresholds based on the first-stage F-statistic for inclusion of the instrument (with a single instrument, just the squared t-statistic) have been proposed in the literature. See Staiger and Stock 1997; Stock, Wright, and Yogo 2002. In the case of the Lupu replication, the first-stage F on ICCPR ratification is 5.21, suggesting a reasonable but not particular strong first-stage estimate. In general, Angrist and Pischke note that in the presence of a weak instrument, IV estimates tend to be very imprecise (209). We consider this a feature rather than a bug of our approach because we consider strong evidence that the intervention actually improves behavior a necessary condition to persuasively conclude that a counteraction mechanism may be operating.
} 
any sensitivity analysis in this case is likely to be both extremely high-variance and potentially misleading.

To demonstrate counteraction through the dual-regression method, researchers must establish that, at minimum, the policy intervention affects the targeted outcome of interest. Without this first step, any counteraction is entirely speculative. Given what we find in replicating Hafner-Burton's main regression, we cannot conclude that the results provide evidence that "governments continue or expand their use of political terror ... to cancel out other improvements governments make but do not want to work." ${ }^{69}$ The replication cannot establish any initial improvement to counteract and the results showing expansion of political terror are themselves questionable given what we expect regarding omitted variable bias. ${ }^{70}$ In sum, we find no support for the article's claims about counteraction.

Next, we turn to Lupu, who primarily focuses on assessing the extent to which the effect of international human rights treaties depends on domestic courts' ability to credibly enforce those rights. He theorizes that civil rights violations are easier to prosecute compared to violations of physical integrity rights (e.g., torture) as a result of variation in the costs of producing evidence. Because governments' abuses of physical integrity rights are much harder to document, courts will be much less able to force governments to abide by international legal commitments with respect to those rights. The theory predicts that ICCPR ratification will improve governments' performance on indicators of civil rights (e.g., freedom of speech, association, etc.) while having no effect

\footnotetext{
${ }^{69}$ Hafner-Burton 2008, abstract.
} 
on performance for indicators of physical integrity rights. Rights measures are taken from the CIRI data set and take on values from 0 to 2 with 0 denoting frequent/severe violations, 1 denoting occasional violations, and 2 denoting no reported violations.

Using a series of ordinal probit regression models estimated on a country-year data set, Lupu finds a positive and statistically significant association between ICCPR ratification and three indicators of civil and political rights from the CIRI data set: freedom of association, freedom of speech, and religious freedom. He finds no statistically significant association between ICCPR ratification and three out of the four physical integrity variables (killings, torture, and imprisonment) but does find that ICCPR ratifiers have worse CIRI ratings on disappearances. The regression models control for measures of judicial independence, democracy (as measured by the Polity IV scale), regime durability, civil war, external war, logged GDP per capita, log population, and a measure of the number of international NGOs the state is a member of. The models also control for the one-year lag of the outcome and include fixed effects for each year.

With the surprising finding of a negative effect for disappearance, Lupu suggests that counteraction may be to blame. While describing the claim as "tentative" he posits that "because ICCPR commitment constrains governments' ability to restrict the freedoms of speech, association, assembly, and religion, they may turn to harsher methods, for which evidence is less costly to hide, to accomplish what they no longer can with less egregious human rights violations." ${ }^{, 11}$ This is clearly a claim about counteraction, in that the constraint placed on civil and political rights is hypothesized to directly influence the expanded use of disappearance.

\footnotetext{
${ }^{71}$ Lupu 2013, 492.
} 


\section{FIGURE 3 ABOUT HERE}

We replicate these four regressions, fitting ordinary least squares regressions of the CIRI score on the same linear additive models proposed in the original paper. ${ }^{72} \mathrm{We}$ also make a few slight corrections to the data to obtain a larger sample size $(2,155$ versus 1,966 as reported in the data). Figure 3 presents our estimated effects of ICCPR ratification on each CIRI score. We replicate the originally reported pattern for measures of association and disappearances. If we assume that conventional significance levels are appropriate -- an important normative question not considered here -- we do not find a statistically significant effect $(\alpha=.05)$ on speech or religious freedom. On average, ICCPR ratifiers have a .06 higher score on association and a .05 lower CIRI score with respect to disappearances.

\section{Implementing the Sensitivity Analysis}

Our method stresses the importance of a sensitivity analysis to help interpret the observed effects and the plausibility of counteraction. Given our finding, what can we say about the plausibility of counteraction between improvements in association rights and the worsening of disappearances? Figure 2 plots the sensitivity analysis for the 2SLS estimate of the counteraction effect for varying levels of the exclusion restriction violation. The light gray line denotes the naive estimate: what our estimated effect would

\footnotetext{
72 We choose not to estimate ordered probit models as in the original paper. In practice, even with nonlinearities in outcome variables, OLS will provide a best linear approximation to the causal response function. Additionally, 2SLS requires linear models for both stages. See Angrist 2001.
} 
be if we believed ICCPR ratification had no effect on disappearances aside from its effect on association rights. In this case, the effect is negative, consistent with counteraction, but imprecisely estimated and not statistically significant at any conventional rejection threshold $(\mathrm{p}=0.177)$. Notably, although the two reduced-form estimates were statistically significant and in opposite directions, implied estimate of the causal effect of one outcome on the other is not statistically significant. This highlights one possible drawback of our method -- we give up some statistical power in exchange for more flexible assumptions. If we were to assume that there is no direct effect of ICCPR ratification on CIRI disappearance -- in other words, assuming that counteraction or a trade-off is the only possible mechanism -- then the estimated average effect of ICCPR ratification on CIRI disappearance would equal the indirect effect and the two-stage approach would be unnecessary unless the specific effect of association on disappearance scores was of interest. However, because we do not want to simply assert that counteraction is the only possible mechanism but instead assess the plausibility of an indirect effect for a variety of possible direct effects, we need to accept some reduction in power to properly conduct inference on the effect of the mediator. For reasonable sample sizes, we consider the reduction in power when $d$ is close to 0 to be far outweighed by the risk of falsely concluding in favor of an indirect effect when there exists a strong direct effect. Since the goal of sensitivity analyses is to be conservative in drawing inferences, we consider the increase in estimation uncertainty to be a reasonable sacrifice.

When we vary the assumed size of the direct effect of ICCPR ratification on CIRI disappearance score, we conclude that there is a small range of direct effects for which we would obtain a statistically significant $(p<.05)$ and negative indirect effect of an 
increase in CIRI association scores on CIRI disappearance scores. Notably, if the direct effect is itself negative (the backlash argument), then the estimated indirect effect is either close to 0 or actually positive. This matches the intuition behind our sensitivity analysis -- the presence of a negative direct effect explains away a counteraction or tradeoff hypothesis. In a setting where counteraction is more plausible, we would see negative and statistically significant effects even when allowing for some amount of backlash. In the case of Lupu, this does not appear to be so.

Instead of asking how much of a negative direct effect is enough to "break" the result, for the Lupu analysis, we consider how much of a positive direct effect is enough to suggest some counteraction. In other words, do we think that the observed effect of the intervention on the spillover outcome is too small compared to what we would expect, suggesting some counteraction. In the Lupu data, we find that to reject the null hypothesis of no counteraction at $\alpha=.05$, the direct effect of ICCPR ratification would have to be positive and equivalent to about .1 standard deviation of the outcome.

\section{FIGURE 4 ABOUT HERE}

The sensitivity analysis is helpful because it helps probe the counteraction claim's plausibility. Importantly, counteraction becomes plausible only when our prior beliefs about the true effect of ICCPR ratification are particularly strong and we need to explain away the "surprise" of a smaller-than-expected finding. Plotting the counteraction effect for varying levels of the exclusion restriction violation illustrates what the estimated effect would be if we believed ICCPR ratification affected disappearances only 
through association rights. The sensitivity analysis thus allows us to consider whether the intervention's observed effect on the spillover outcome is too small compared to what we would expect, which would suggest some counteraction. In the case of Lupu, we find that to reject the null hypothesis of no counteraction, the direct effect of ICCPR ratification would have to be positive and about .1 standard deviation of the outcome. While a 0.1 standard deviation effect may seem somewhat small, suggesting plausibility of counteraction, in this context, it is more sensible to compare to a known benchmark effect. The vertical dark gray line in Figure 4 denotes the estimated counteraction effect if we assume that the direct effect of ICCPR ratification on the disappearance score was of the same standardized size as ICCPR ratification's effect on the association rights score. Even if this were true, our analysis would fail to reject the null of no effect at $\alpha=.05$.

We emphasize the importance of finding plausible bounding values for the direct effect when conducting the sensitivity analyses because it is always possible to find a range of direct effect parameter values that would yield both strong positive and strong negative indirect effect estimates. Analogous work on sensitivity analyses for the case of unobserved confounding has often proposed relying on relationships between observed quantities and the outcome of interest as "benchmarks" for determining what is a reasonable magnitude of unobserved confounding -- for example, arguing that a result is robust to an unobserved confounder that is as strong as the strongest observed predictor of treatment and outcome. ${ }^{73}$ However, we caution against using any single benchmarking approach that is not informed by substantive knowledge. As Cinelli and

\footnotetext{
${ }^{73}$ However, see recent work by Cinelli and Hazlett 2020 (Appendix A.2) arguing that informal benchmarking approaches for unobserved confounding can be highly misleading because the true effects of observed confounders used as benchmarks may not be identifiable from the regressions omitting the unobserved confounder.
} 
Hazlett argue, sensitivity analyses provide a basis for "principled argument" rather than an "automatic procedure" for assessing the underlying research design's correctness. ${ }^{74}$ Therefore, our recommendation to begin with the "first-stage" effect of $A_{i}$ on $M_{i}$ as a benchmark for the direct effect of $A_{i}$ on $M_{i}$ should be understood as the first step in assessing plausible direct effect values and not the final one. A researcher's goal in selecting reasonable sensitivity parameters is to determine how large of an effect the intervention could have in general on any outcome and then assess how these effects would compare in size to the unobserved direct effect of $A_{i}$ on the specific outcome $Y_{i}$. Subject matter knowledge about the known effects of the intervention should guide researchers here.

If an intervention is known to have relatively weak effects on most relevant outcomes and $Y_{i}$ is not uniquely different from those outcomes, then that suggests values of the sensitivity parameter far away from 0 are unlikely. One reasonable approach to quantifying this may be to benchmark the direct effect of $A_{i}$ on $Y_{i}$ using the largest known effect of $A_{i}$ on any outcome. We recommend starting with the effect of $A_{i}$ on $M_{i}$ precisely because its identification is a prerequisite to the exercise of assessing counteraction and because researchers are likely to have existing beliefs about the relative size of this effect compared to others. However, estimating effects on other outcomes may be useful as well, with the caveat that the set of controls needed to identify the effect of $A_{i}$ on $M_{i}$ may not be the same set needed to identify the effect of the intervention on all relevant outcomes. The choice of reasonable bounding values will always involve a combination of quantitative knowledge about the general effects of the intervention with

\footnotetext{
${ }^{74}$ Cinelli and Hazlett 2020.
} 
qualitative knowledge about how those effects compare with the unobserved direct effect on the outcome of interest.

We can illustrate this combination of quantitative and qualitative knowledge using Lupu's theoretical argument for counteraction. The domestic courts theory posits that because courts are more capable of enforcing civil rights compared to physical integrity rights as a result of differences in the availability of information, the effect of an international rights commitment will be larger for civil rights than for physical integrity rights. The direct effect of ICCPR ratification on personal integrity rights is therefore unlikely to be greater than the effect of ratification on civil rights, making the estimated effect of $A_{i}$ on $M_{i}$ a plausible extreme bound for the sensitivity parameter. Based on this benchmark, the most feasible values for ratification's direct effect will lie to the left of the dark gray line in Figure 4, all of which imply no statistically significant counteraction effect. In other words, Lupu introduced a counteraction hypothesis to explain the appearance of an effect where he anticipated finding a null based on a theoretical argument that predicted a direct effect of ICCPR ratification close to zero -- governments ratifying human rights treaties are unlikely to face significant litigation with respect to personal integrity rights compared to civil rights and therefore have fewer incentives for improvement. However, a formal analysis suggests that the gap between what was expected and what was observed does not provide much evidence for counteraction. The small but surprising negative effect on disappearances is not sufficiently surprising for us to conclude that counteraction is occurring.

\section{Conclusion}


We live in a world where, despite the best efforts of well-meaning advocates, human rights violations continue. The determination of some leaders to maintain power and privilege through repression has led to widespread speculation that human rights advocates may actually exacerbate rather than alleviate the problem. ${ }^{75}$ Critics suggest that resources have been shifting to the hopeless quest of improving rights (at the expense of development, equality, or social justice); targeted governments and their populations are starting to lash back against international pressure; and clever despots have connived to replace open violations with stealth repression. These accounts allege that the international human rights project is worse than ineffective.

Such negative consequences are just as important to understand as any other effect, but they should be subject to the same evidentiary standards as the rest of social science. We have discussed at least three types mechanisms to explain negative spillovers of human right interventions -- backlash, trade-offs, and counteraction -- that scholars have recently offered as reasons to throttle back on international human rights efforts. These claims may be plausible; all merit serious attention. But only a few researchers provide systematic evidence for such claims. Even fewer provide evidence that support their causal arguments.

Unfortunately, evidence from the effects of interventions alone is insufficient to demonstrate the existence of a particular causal mechanism when the claimed effect is theorized to be indirect or mediated. As a first-order concern, inference on the overall effects of interventions is extremely challenging because interventions target problem-

\footnotetext{
${ }^{75}$ Kennedy 2002.
} 
ridden countries, generating a significant degree of potential omitted variable bias. However, even if we grant that researchers have credibly identified the first-order effects of these interventions, their leap to making conclusions about the second-order effects and their underlying mechanisms requires additional assumptions regarding the underlying causal structure that may not be credible.

We have outlined three mechanisms by which interventions to improve human rights may have negative spillover effects on other outcomes. Counteraction is one such mechanism which we carefully define as a change in state behavior such that either the incidence or level of a spillover outcome increases in a way that is attributable to the change in the targeted outcome driven by the intervention. We connect this to the concept of a mediation or indirect effect in the causal inference literature and note the importance of showing a strong first-order effect of the intervention as a prerequisite to any theorizing about counteraction mechanisms. Unless the intervention has, ceteris paribus, some positive consequences, there is nothing to counter and there is no mediation.

This is not to claim that governments who sign human rights treaties or experience harsh external criticisms do not (often, perhaps) do very bad things. But the counteraction theory requires a demonstration both that the external treatment caused bad results, and that the causal mechanism driving this effect is an improvement in the targeted area of rights. In much of the literature, there is very little scrutiny given to such causal claims, even though such mechanisms are harder to assess empirically than "black box" correlations. ${ }^{76}$

\footnotetext{
${ }^{76}$ Green, Ha, and Bullock 2010.
} 
If researchers are going to use quantitative data to assess mechanisms like counteraction, they need to model it explicitly. We have presented a method for assessing counteraction that requires fewer assumptions than a full causal mediation analysis and can be easily adapted to the regression approaches researchers often use for estimating the effects of interventions. In the two cases we explore, both of which suggest that interventions caused compensatory actions by governments, we find that either there exists no first-order impact of the hypothesized intervention or the intervention's expected direct impact on the spillover outcome would have had to be so large and so positive as to be implausible given our theoretical expectations. We conclude that it is far more likely that deteriorating rights have more to do with garden-variety selection effects or possibly alternative mechanisms than they do with strategic counteraction.

We focused primarily on counteraction because quantitative research has been used to back such claims. But the approach we suggest is appropriate for any theory that links unintended outcomes to mediated, or indirect effects. For example, claims about budgetary trade-offs would have to show that by making human rights a priority, some other indicator of human welfare, such as social justice, suffered a reduction in resources that in turn accounts for growing inequality. Similarly, arguments that the very task of improving human rights has negative downstream consequences will be more convincing when they demonstrate that human rights law and advocacy has first had its intended effect of improving rights -- that is, there is some positive rights outcome to counter. The 
methods we propose could be used to shed light on a range of claims about unintended consequences found loosely stated in the literature. ${ }^{77}$

Our general approach can also be useful, in somewhat modified form, to test for unintended consequences in other issue areas. For example, a government facing a budget constraint might choose to fund technologies that replace coal power plants, but scale back efforts to reduce automobile emissions (trade-offs); might oppose plans to reduce carbon emissions by stimulating political or social resistance (backlash) or might respond to pressure to reduce carbon emissions by requiring an expensive technology, but counter the effects of that on companies by allowing them to lower their standards in another area to offset those costs, essentially then merely shifting a pollution problem from one type to another (counteraction).

Negative consequences to human rights advocacy warrant continued vigilance, and the concerns of researchers who have hypothesized trade-offs, backlash, and counteraction are utterly valid. But there is a danger to attributing harm to international human rights law and advocacy when they are not the cause. Counteraction is a particularly serious mechanism since its existence implies that no intervention could potentially improve rights across the board since improving rights in one area would cause denigration of human rights in other areas to compensate for the improvements. The risk of discouraging promotion of international human rights norms based on underidentified causal mechanisms is very serious indeed. Statistical science aside, we would argue that even if committing to and advocating international human rights sometimes

\footnotetext{
${ }^{77}$ For example, a backlash argument, as we discussed could also be unmediated: backlash could focus on the intervention per se, even if rights never improve.
} 
cause some harm, this would not necessarily justify silence. Rather, it should prompt consideration of means to blunt the effects of counteraction. While this is not the place to elaborate, we think moral grounds alone might justify continued rhetorical and substantive support for international human rights. These are philosophical and practical questions for policymakers and the international community to answer together. Our purpose has been to avoid unsupported inferences and point a way toward investigating these issues more rigorously to implement the most effective policies to improve human rights for the world's most vulnerable populations.

Data Availability Statement

Replication files for this article may be found at https: doi.org/10.7910/DVN/1NTFKO

\section{Supplementary Material}

Supplementary material for this article is available at International Organization. 
References

Acharya, Avidit, Matthew Blackwell, and Maya Sen. 2016. Explaining Causal Findings Without Bias: Detecting and Assessing Direct Effects. American Political Science Review 110 (3):512 --- 29.

Ahmed, Faisal. 2012. The Perils of Unearned Foreign Income: Aid, Remittances, and Government Survival. American Political Science Review 106 (1):146 --- 65.

Alvi, Shahzad, and Ather Maqsood Ahmed. 2014. Analyzing the Impact of Health and Education on Total Factor Productivity: A Panel Data Approach. Indian Economic Review 49 (1):109 --- 23.

Ambrosio, Thomas. 2016. Authoritarian Backlash: Russian Resistance to Democratization in the Former Soviet Union. Routledge.

Angrist, Joshua D. 2001. Estimation of Limited Dependent Variable Models with Dummy Endogenous Regressors: Simple Strategies for Empirical Practice. Journal of Business and Economic Statistics 19 (1):2 --- 28.

Angrist, Joshua D., and Guido W. Imbens. 1995. Two-Stage Least Squares Estimation of Average Causal Effects in Models with Variable Treatment Intensity. Journal of the American Statistical Association 90 (430):431 --- 42.

Angrist, Joshua D., Guido W. Imbens, and Donald B. Rubin. 1996. Identification of Causal Effects Using Instrumental Variables. Journal of the American Statistical Association 91 (434):444 --- 55.

Arendt, Hannah. 1970. On Violence. Houghton Mifflin Harcourt.

Aronow, Peter M., and Cyrus Samii. 2016. Does Regression Produce Representative Estimates of Causal Effects? American Journal of Political Science 60 (1):250 --67.

Baron, Reuben M., and David A. Kenny. 1986. The Moderator --- Mediator Variable Distinction in Social Psychological Research: Conceptual, Strategic, and Statistical Considerations. Journal of Personality and Social Psychology 51 (6):1173 --- 82.

Bell, Sam R., K. Chad Clay, and Amanda Murdie. 2012. Neighborhood Watch: Spatial Effects of Human Rights INGOs. The Journal of Politics 74 (2):354 --- 68.

Calver, Matthew. 2015. Closing the Aboriginal Education Gap in Canada: The Impact on Employment, GDP, and Labour Productivity. International Productivity Monitor (28): 27 --- 46.

Carothers, Thomas. 2003. Promoting the Rule of Law Abroad: The Knowledge Problem. The Carnegie Endowment for International Peace. Accessed 3 November 2020 from <www.jstor.org/stable/resrep12978>.

Chaudoin, Stephen, Jude Hays, and Raymond Hicks. 2018. Do We Really Know the WTO Cures Cancer? British Journal of Political Science 48 (4):903 --- 28.

Cinelli, Carlos, and Chad Hazlett. 2020. Making Sense of Sensitivity: Extending Omitted Variable Bias. Journal of the Royal Statistical Society: Series B (Statistical Methodology) 82 (1):39 --- 67.

Cohen, Jacob. 1992. A Power Primer. Psychological Bulletin 112 (1):155 --- 59.

Conley, Timothy G., Christian B. Hansen, and Peter E. Rossi. 2012. Plausibly Exogenous. Review of Economics and Statistics 94 (1):260 --- 72.

Conrad, Courtenay R., and Will H. Moore. 2010. What Stops the Torture? American Journal of Political Science 54 (2):459 --- 76. 
Conrad, Courtenay R., and Emily Hencken Ritter. 2013. Treaties, Tenure, and Torture: The Conflicting Domestic Effects of International Law. The Journal of Politics 75 (2):397 --- 409.

Conrad, Courtenay R., and Jacqueline H.R. DeMeritt. 2014. Unintended Consequences: The Effect of Advocacy to End Torture on Empowerment Rights Violations. In Examining Torture: Empirical Studies of State Repression, edited by Tracy Lightcap and James P. Pfiffner, 159 --- 83. Palgrave Macmillan.

Davenport, Christian. 2007. State Repression and Political Order. Annual Review of Political Science 10:1 --- 23.

Daxecker, Ursula. 2017. Dirty Hands: Government Torture and Terrorism. Journal of Conflict Resolution 61 (6):1261 --- 89.

Downs, George W., David M. Rocke, and Peter N. Barsoom. 1996. Is the Good New About Compliance Good News About Cooperation? International Organization 50 (3):379 --- 406.

Dreher, Axel, Martin Gassebner, and Lars-H.R. Siemers. 2012. Globalization, Economic Freedom, and Human Rights. Journal of Conflict Resolution 56 (3):516 --- 46.

Epprecht, Marc. 2012. Sexual Minorities, Human Rights and Public Health Strategies in Africa. African Affairs 111 (443):223 --- 43.

Ertefaie, Ashkan, Dylan S. Small, James H. Flory, and Sean Hennessy. 2017. A Tutorial on the Use of Instrumental Variables in Pharmacoepidemiology.

Pharmacoepidemiology and Drug Safety 26 (4):357 --- 67.

Fägerlind, Ingemar, and Lawrence J. Saha. 2014. Education and National Development: A Comparative Perspective. Elsevier.

Fariss, Christopher J., and Keith E. Schnakenberg. 2014. Measuring Mutual Dependence Between State Repressive Actions. Journal of Conflict Resolution 58 (6):1003 --32.

Franklin, James C. 2008. Shame on You: The Impact of Human Rights Criticism on Political Repression in Latin America. International Studies Quarterly 52 (1):187 --- 211.

Green, Donald P., Shang E. Ha, and John G. Bullock. 2010. Enough Already About "Black Box" Experiments: Studying Mediation Is More Difficult Than Most Scholars Suppose. The Annals of the American Academy of Political and Social Science 628 (1):200 --- 208.

Hafner-Burton, Emilie M. 2008. Sticks and Stones: Naming and Shaming the Human Rights Enforcement Problem. International Organization 62 (4):689 --- 716.

Harris, Richard, and Godwin Arku. 2006. Housing and Economic Development: The Evolution of an Idea Since 1945. Habitat International 30 (4):1007 --- 17.

Helfer, Laurence R. 2017. Overlegalizing Human Rights: International Relations Theory and the Commonwealth Caribbean Backlash Against Human Rights Regimes. In International Law and Society, 125 --- 204. Routledge.

Hopgood, Stephen, Jack Snyder, and Leslie Vinjamuri. 2017. Introduction: Human Rights Past, Present and Future. In Human Rights Futures, edited by Stephen Hopgood, Jack Snyder, and Leslie Vinjamuri, 1 --- 23. Cambridge University Press.

Huber, Martin. 2014. Sensitivity Checks for the Local Average Treatment Effect. Economics Letters 123 (2):220 --- 23. 
Hurd, Elizabeth Shakman. 2017. Governing Religion as Right. In Human Rights Futures, edited by Stephen Hopgood, Jack Snyder and Leslie Vinjamuri, 189 --- 212. Cambridge University Press.

Ichino, Nahomi, and Matthias Schündeln. 2012. Deterring or Displacing Electoral Irregularities? Spillover Effects of Observers in a Randomized Field Experiment in Ghana. The Journal of Politics 74 (1):292 --- 307.

Imai, Kosuke, Luke Keele, Dustin Tingley, and Teppei Yamamoto. 2011. Unpacking the Black Box of Causality: Learning About Causal Mechanisms from Experimental and Observational Studies. American Political Science Review 105 (4):765 --- 89.

Imbens, Guildo W. 2003. Sensitivity to Exogeneity Assumptions in Program Evaluation. American Economic Review 93 (2):126 --- 32.

Kelley, Judith. 2011. Do International Election Monitors Increase or Decrease Opposition Boycotts? Comparative Political Studies 44 (11):1527 --- 56.

Kennedy, David. 2002. International Human Rights Movement: Part of the Problem? Harvard Human Rights Journal 15 (3):101 --- 26.

Kennedy, David. 2004. The Dark Sides of Virtue: Reassessing International Humanitarianism. Princeton University Press.

Kleinfeld, Rachel. 2012. Advancing the Rule of Law Abroad: Next Generation Reform. Brookings Institution Press.

Kraay, Aart. 2012. Instrumental Variables Regressions with Uncertain Exclusion Restrictions: A Bayesian Approach. Journal of Applied Econometrics 27 (1):108 $--28$.

Kuperman, Alan J. 2004. The Limits of Humanitarian Intervention: Genocide in Rwanda. Brookings Institution Press.

Lupu, Yonatan. 2013. Best Evidence: The Role of Information in Domestic Judicial Enforcement of International Human Rights Agreements. International Organization 67 (3):469 --- 503.

MacKinnon, David P., Chondra M. Lockwood, Jeanne M. Hoffman, Stephen G. West, and Virgil Sheets. 2002. A Comparison of Methods to Test Mediation and Other Intervening Variable Effects. Psychological Methods 7 (1):83 --- 104.

Moore, Will H. 1998. Repression and Dissent: Substitution, Context, and Timing. American Journal of Political Science 42 (3): 851 --- 73.

Moore, Will H. 2000. The Repression of Dissent: A Substitution Model of Government Coercion. Journal of Conflict Resolution 44 (1):107 --- 27.

Morrison, Kevin. 2009. Oil, Nontax Revenue, and the Redistributional Foundations of Regime Stability. International Organization 63 (1):107 --- 38.

Moyn, Samuel. 2010. The Last Utopia: Human Rights in History. Belknap/Harvard University Press.

Murdie, Amanda, and Tavishi Bhasin. 2011. Aiding and Abetting: Human Rights INGOs and Domestic Protest. Journal of Conflict Resolution 55 (2):163 --- 91.

Murdie, Amanda, and David Davis. 2012. Shaming and Blaming: Using Events Data to Assess the Impact of Human Rights INGOs. International Studies Quarterly 56 (1):1 --- 16.

Neyman, Jerzy. 1923. On the Application of Probability Theory to Agricultural Experiments. Essay on Principles. Section 9. Statistical Science 5 (4):465 --- 72. 
Oster, Emily. 2019. Unobservable Selection and Coefficient Stability: Theory and Evidence. Journal of Business and Economic Statistics 37 (2):187 --- 204.

Pearl, Judea. 2000. Causality: Models, Reasoning, and Inference. Cambridge University Press.

Pearl, Judea. 2001. Direct and Indirect Effects. In Proceedings of the Seventeenth Conference on Uncertainty in Artificial Intelligence, 411 --- 420. Morgan Kaufmann.

Posner, Eric A. 2008. Human Welfare, Not Human Rights. Columbia Law Review 108: 1758 --- 801.

Rafi, Mohammad, and A.M.R. Chowdhury. 2000. Human Rights and Religious Backlash: The Experience of a Bangladeshi NGO. Development in Practice 10 (1):19 --- 30.

Rejali, Darius M. 2007. Torture and Democracy. Princeton University Press.

Risse, Thomas, and Kathryn Sikkink. 1999. The Socialization of International Human Rights Norms into Domestic Practice: Introduction. In The Power of Human Rights: International Norms and Domestic Change, edited by Thomas Risse, Steve C. Ropp, and Kathryn Sikkink, 1 --- 38. Cambridge University Press.

Robins, James M., and Sander Greenland. 1992. Identifiability and Exchangeability for Direct and Indirect Effects. Epidemiology 3 (2): 143 --- 55.

Rosenbaum, Paul R. 2002. Observational Studies. 2nd ed. Springer.

Rubin, Donald B. 1974. Estimating Causal Effects of Treatments in Randomized and Nonrandomized Studies. Journal of Educational Psychology 66 (5):688 --- 701.

Schedler, Andreas. 2002. The Menu of Manipulation. Journal of Democracy 13 (2):36 --50 .

Scheff, Thomas J. 2000. Shame and the Social Bond: A Sociological Theory. Sociological Theory 18 (1):84 --- 99.

Sikkink, Kathryn. 2013. The United States and Torture: Does the Spiral Model Work? In The Persistent Power of Human Rights: From Commitment to Compliance, edited by Thomas Risse, Steve C. Ropp, and Kathryn Sikkink, 145 --- 63. Cambridge University Press.

Simmons, Beth A. 2009. Mobilizing for Human Rights: International Law in Domestic Politics. Cambridge University Press.

Simmons, Beth A., and Anton Strezhnev. 2017. Human Rights and Human Welfare: Looking for a "Dark Side" to International Human Rights Law. In Human Rights Futures, edited by Stephen Hopgood, Jack Snyder. and Leslie Vinjamuri, 60 --87. Cambridge University Press.

Simpser, Alberto, and Daniela Donno. 2012. Can International Election Monitoring Harm Governance? The Journal of Politics 74 (2):501 --- 13.

Snyder, Jack. 2019. Backlash Against Human Rights Shaming: Emotions in Groups. International Theory 12 (1):109 --- 32.

Sobel, Michael E. 2008. Identification of Causal Parameters in Randomized Studies with Mediating Variables. Journal of Educational and Behavioral Statistics 33 (2):230 $---51$.

Staiger, Douglas, and James H. Stock. 1997. Instrumental Variables Regression with Weak Instruments. Econometrica 65 (3):557 --- 86. 
Stock, James H., Jonathan H. Wright, and Motohiro Yogo. 2002. A Survey of Weak Instruments and Weak Identification in Generalized Method of Moments. Journal of Business and Economic Statistics 20 (4):518 --- 29.

Thomas, Daniel C. 2001. The Helsinki Effect: International Norms, Human Rights, and the Demise of Communism. Princeton University Press.

Tsutsui, Kiyoteru, Claire Whitlinger, and Alwyn Lim. 2012. International Human Rights Law and Social Movements: States' Resistance and Civil Society's Insistence. Annual Review of Law and Social Science 8:367 --- 96.

VanderWeele, Tyler J., and Stijn Vansteelandt. 2009. Conceptual Issues Concerning Mediation, Interventions and Composition. Statistics and Its Interface 2 (4):457 -- 68.

Vinjamuri, Leslie. 2017. Human Rights Backlash. In Human Rights Futures, edited by Stephen Hopgood, Jack Snyder, and Leslie Vinjamuri, 114 --- 34. Cambridge University Press.

Vreeland, James Raymond. 2008. Political Institutions and Human Rights: Why Dictatorships Enter into the United Nations Convention Against Torture. International Organization 62 (1):65 --- 101.

Wald, Abraham. 1940. The Fitting of Straight Lines If Both Variables Are Subject to Error. The Annals of Mathematical Statistics 11 (3):284 --- 300.

Weiss, Thomas, David Cortright, George Lopez, and Larry Minear. 1997. Political Gain and Civilian Pain: Humanitarian Impacts of Economic Sanctions. Rowman and Littlefield.

Wood, Reed M. 2008. "A Hand Upon the Throat of the Nation": Economic Sanctions and State Repression, 1976 --- 2001. International Studies Quarterly 52 (3):489 --513.

Zhao, Xinshu, John G. Lynch Jr, and Qimei Chen. 2010. Reconsidering Baron and Kenny: Myths and Truths About Mediation Analysis. Journal of Consumer Research 37 (2):197 --- 206. 
TABLE 1. The logic of three spillovers: backlash, trade-offs, and counteraction

\begin{tabular}{|l|l|l|l|l|}
\hline & Description & Condition & Mechanism & Outcome \\
\hline \multirow{5}{*}{ Backlash } & $\begin{array}{l}\text { A policy intervention aimed at improving } \\
\text { human rights (M) triggers a broad reaction } \\
\text { or countermobilization that ultimately } \\
\text { causes a worsening in one area of human } \\
\text { rights (Y) irrespective of any realized } \\
\text { improvements }\end{array}$ & $\begin{array}{l}\text { M and Y are } \\
\text { related, but } \\
\text { may be } \\
\text { complements } \\
\text { or substitutes }\end{array}$ & $\begin{array}{l}\text { Socially } \\
\text { generated } \\
\text { reaction }\end{array}$ & $\begin{array}{l}\text { M: agnostic } \\
\text { Y: worsens }\end{array}$ \\
\hline \multirow{5}{*}{ Trade-offs } & $\begin{array}{l}\text { A policy intervention prioritizes one area } \\
\text { of human rights (M), thereby reducing } \\
\text { attention to other issue areas (Y), } \\
\text { (economic development, equality, justice). } \\
\text { The result is a worsening in the other issue } \\
\text { area(s). }\end{array}$ & $\begin{array}{l}\text { M and Y are } \\
\text { strict } \\
\text { substitutes }\end{array}$ & $\begin{array}{l}\text { Resource } \\
\text { constraint } \\
\text { unintentionally } \\
\text { forces a trade- } \\
\text { off }\end{array}$ & M: worsens \\
\hline Counteraction & $\begin{array}{l}\text { A policy intervention improves human } \\
\text { rights in one area (M). As a direct } \\
\text { consequence of this improvement, changes } \\
\text { in government behavior result in a } \\
\text { worsening of human rights in another } \\
\text { sector (Y). }\end{array}$ & $\begin{array}{l}\text { Violator(s) } \\
\text { views M and } \\
\text { Y as } \\
\text { substitutes }\end{array}$ & $\begin{array}{l}\text { Strategic elite } \\
\text { choice under } \\
\text { the constraint } \\
\text { of monitoring, } \\
\text { obligation, or } \\
\text { shaming }\end{array}$ & $\begin{array}{l}\text { M: improves } \\
\text { Y: worsens }\end{array}$ \\
\hline
\end{tabular}

Note: $\mathrm{M}=$ targeted violation; $\mathrm{Y}=$ spillover effect 


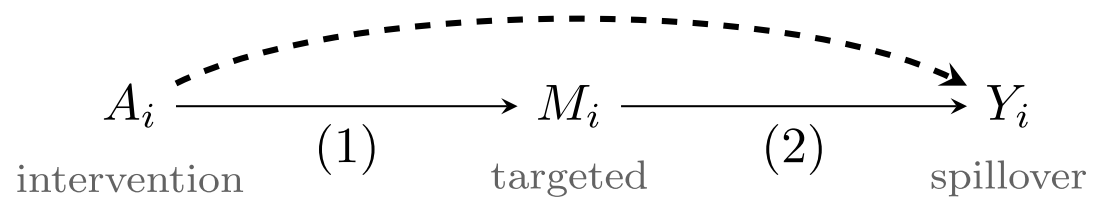

FIGURE 1. Graphical representation of causal pathways

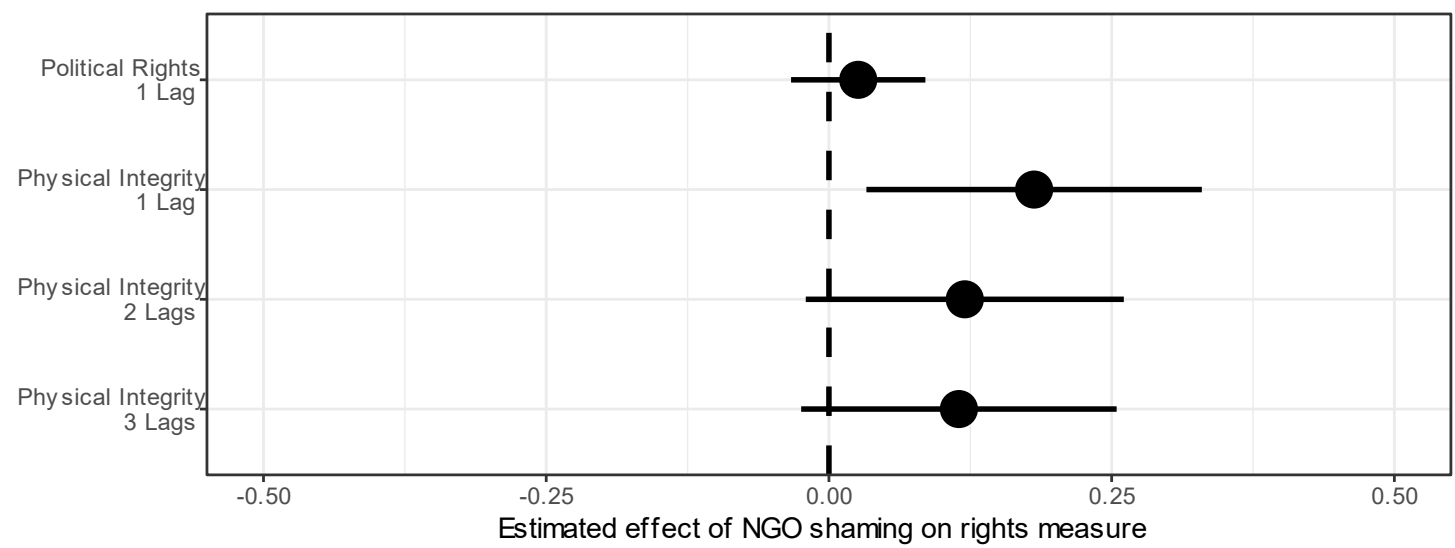

Notes: Point estimates denote coefficients on the standardized logged Amnesty International coverage variable from OLS regression with all covariates + year fixed effects. Lines denote 95 percent robust standard errors clustered by country. $N=2,173$, Countries $=140$; Coverage: 1984 --- 2001.

FIGURE 2. Replication of main effects of NGO shaming from Hafner-Burton 2008 


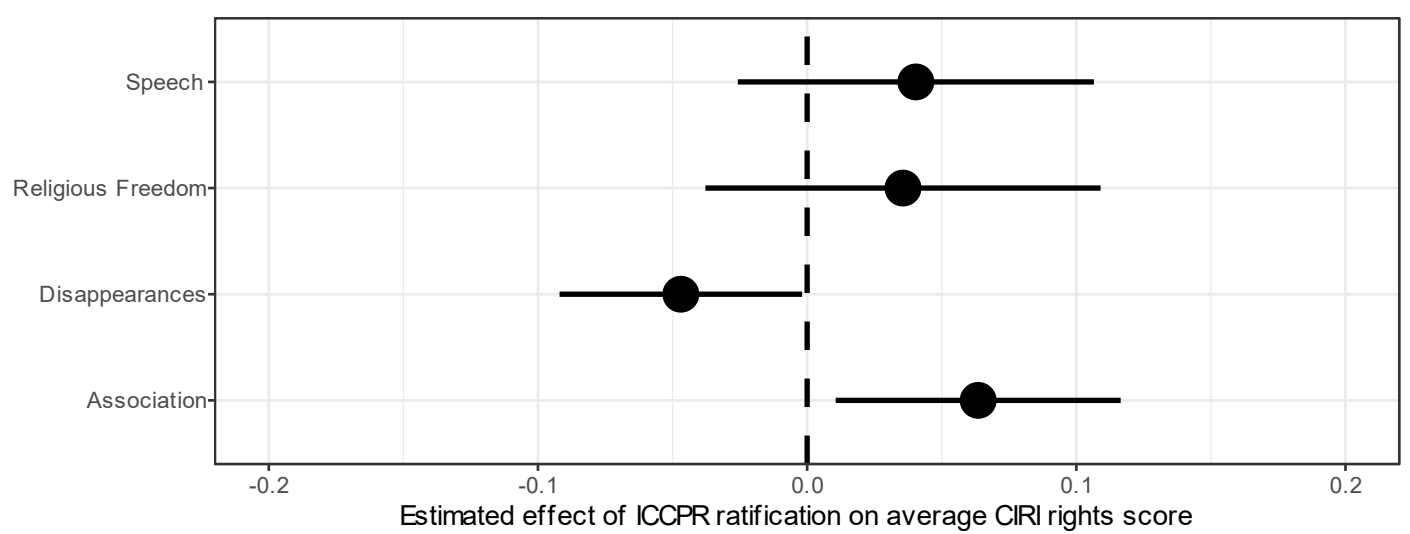

Notes: Point estimates denote coefficients on ICCPR ratification from OLS regression with all covariates + year fixed effects. Lines denote 95 percent robust standard errors clustered by country. $N=2,155$, Countries = 144; Coverage: 1982 --- 1999.

FIGURE 3. Replication of main effects of ICCPR ratification from Lupu 2013

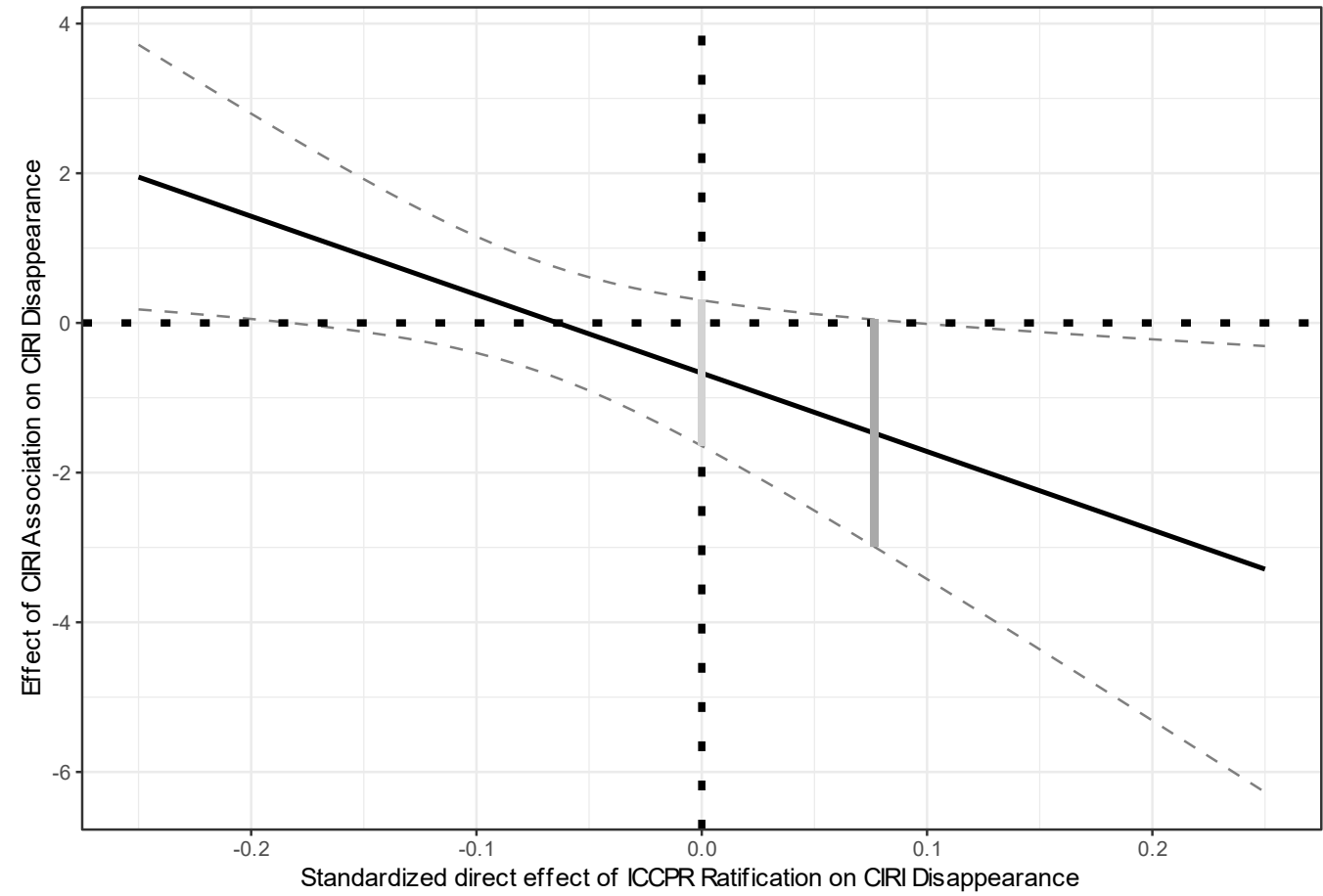

Notes: Solid black line denotes point estimate from 2SLS. Dotted lines denote 95 percent robust confidence intervals clustered by country. Light gray line denotes estimate assuming no direct effect of ICCPR ratification. Dark gray line denotes estimate assuming the magnitude of the direct effect was equal to the magnitude for the effect of ICCPR ratification on CIRI association score. First stage F-statistic on ICCPR ratification $=5.21$

FIGURE 4. Sensitivity analysis for counteraction in Lupu 2013 